\title{
Sea surface freshening inferred from SMOS and ARGO salinity: impact of rain
}

\author{
J. Boutin ${ }^{1}$, N. Martin ${ }^{1}$, G. Reverdin ${ }^{1}$, X. Yin ${ }^{1}$, and F. Gaillard ${ }^{2}$ \\ ${ }^{1}$ CNRS-INSU, UMR7159, LOCEAN/IPSL (CNRS-UPMC-IRD-MNHN), Paris, France \\ ${ }^{2}$ IFREMER, LPO (CNRS-IFREMER-IRD-UBO), Plouzané, France \\ Correspondence to: J. Boutin (jb@locean-ipsl.upmc.fr) \\ Received: 27 July 2012 - Published in Ocean Sci. Discuss.: 18 October 2012 \\ Revised: 17 January 2013 - Accepted: 19 January 2013 - Published: 22 February 2013
}

\begin{abstract}
The sea surface salinity (SSS) measured from space by the Soil Moisture and Ocean Salinity (SMOS) mission has recently been revisited by the European Space Agency first campaign reprocessing. We show that, with respect to the previous version, biases close to land and ice greatly decrease. The accuracy of SMOS SSS averaged over 10 days, $100 \times 100 \mathrm{~km}^{2}$ in the open ocean and estimated by comparison to ARGO (Array for Real-Time Geostrophic Oceanography) SSS is on the order of 0.3-0.4 in tropical and subtropical regions and 0.5 in a cold region. The averaged negative SSS bias $(-0.1)$ observed in the tropical Pacific Ocean between $5^{\circ} \mathrm{N}$ and $15^{\circ} \mathrm{N}$, relatively to other regions, is suppressed when SMOS observations concomitant with rain events, as detected from SSM/Is (Special Sensor Microwave Imager) rain rates, are removed from the SMOS-ARGO comparisons. The SMOS freshening is linearly correlated to $\mathrm{SSM} / \mathrm{Is}$ rain rate with a slope estimated to $-0.14 \mathrm{~mm}^{-1} \mathrm{~h}$, after correction for rain atmospheric contribution. This tendency is the signature of the temporal SSS variability between the time of SMOS and ARGO measurements linked to rain variability and of the vertical salinity stratification between the first centimeter of the sea surface layer sampled by SMOS and the $5 \mathrm{~m}$ depth sampled by ARGO. However, given that the whole set of collocations includes situations with ARGO measurements concomitant with rain events collocated with SMOS measurements under no rain, the mean -0.1 bias and the negative skewness of the statistical distribution of SMOS minus ARGO SSS difference are very likely the mean signature of the vertical salinity stratification. In the future, the analysis of ongoing in situ salinity measurements in the top $50 \mathrm{~cm}$ of the sea surface and of Aquarius satel-
\end{abstract}

lite SSS are expected to provide complementary information about the sea surface salinity stratification.

\section{Introduction}

There is increasing evidence that part of the multi-decadal trends observed on sea surface salinity (SSS), e.g. the western tropical Pacific has become fresher (Cravatte et al., 2009) and the subtropical North Atlantic has become saltier (Gordon and Giulivi, 2008), are due to changes in the global water cycle. This has been pointed out in recent studies (Durack et al., 2012; Terray et al., 2011) which combine observed SSS changes and climate model simulations in order to assess the origin of the SSS changes. As a consequence, there is a strong need for well sampled SSS time series both for monitoring the changes and for deepening the respective roles of the atmosphere and ocean dynamics and thermodynamics and air-sea interactions on the observed SSS changes. It is expected that the new satellite SSS missions, the Soil Moisture and Ocean Salinity (SMOS) mission and the Aquarius mission, will provide new SSS data sets, complementary to in situ measurements (Lagerloef et al., 2010).

Today, the ARGO array (Array for Real-Time Geostrophic Oceanography) provides the best synoptic coverage of in situ salinity over the global ocean (see for instance http: //www.coriolis.eu.org). ARGO is a global array of over 3000 free-drifting profiling floats that measure temperature and salinity in the upper $2000 \mathrm{~m}$ of the ocean every ten days; the upper salinity is measured at a few meters depth. With respect to the ARGO array, which provides about one measurement every $3^{\circ}$, the ship measurements provide a much better sampling allowing a much better location of SSS gradients 
along ship tracks at the expense of a worse synoptic coverage. Ship salinity is also measured at a few meters depth. Prior to SMOS launch, Hénocq et al. (2010) have shown that in rainy regions, in situ salinity measured at various depths between $1 \mathrm{~m}$ and $10 \mathrm{~m}$ differ by 0.1 to 0.5 in $20 \%$ of the cases and that care should be taken for validating and interpreting satellite SSS in rainy regions. Actually, large freshenings (several tenths of salinity unit) can develop in the upper few meters of the ocean after a heavy rainfall, as clearly evidenced during the Tropical Oceans-Global Atmosphere Coupled Ocean-Atmosphere Response Experiment (TOGA COARE) (Soloviev and Lukas, 1996, 1997). The sea surface salinity freshening between $15 \mathrm{~cm}$ and $50 \mathrm{~cm}$ depth in the tropical oceans has been further documented using surface autonomous drifters (Reverdin et al., 2012); on average over all the sampled events, the salinity drawdown of isolated rainfall events averaged $0.56 \mathrm{psu}$, and water was about 0.1 fresher at $15 \mathrm{~cm}$ than at $45 \mathrm{~cm}$ depth, this gradient disappearing after, typically, four hours.

The SSS measured from space by microwave radiometers operating at L-band $(1.4 \mathrm{GHz})$, like SMOS and Aquarius, is representative of the first centimeter of the sea surface. The goal of these missions is to provide an accuracy of 0.2 on SSS averaged over GODAE (Global Ocean Data Assimilation Experiment) scales (typically $200 \times 200 \mathrm{~km}^{2}$ and 10 days or $100 \times 100 \mathrm{~km}^{2}$ and one month). The ocean haline skin layer, due to surface evaporation, is expected to be much thinner $(\sim 60 \mu \mathrm{m})$ than the electromagnetic penetration depth at L-band so that the effect of the sea surface salinity sublayer on satellite SSS is estimated to be less than 0.01 , i.e. negligible compared to other error sources in SSS remote sensing (Zhang and Zhang, 2012). Hence, the main geophysical sources of variation between satellite and in situ salinity are expected to be linked to vertical salinity stratifications especially in rainy and river outflow regions and to sharp oceanic fronts. In this paper, we study the observed SMOS and ARGO salinity differences, as ARGO SSS are widely used for validating satellite SSS and we focus on differences observed in the rainy region of the InterTropical Convergence Zone (ITCZ) of the Pacific Ocean.

After a description of the measurements and the methods (Sect. 2), a validation of SMOS SSS over the global ocean, and in four specific regions is presented (Sect. 3). Then, we detail the SMOS minus ARGO SSS differences with respect to satellite rain rate (Sect. 4). We discuss these results in view of error sources in Sect. 5; conclusions and perspectives are given in Sect. 6 .

\section{Data and methods}

Our study concentrates on the period from 1 July 2010 to 30 September 2010. This period follows the SMOS commissioning period during which the SMOS instrument configuration was varying (Mecklenburg et al., 2012). In addition, the influence of the galactic noise on SMOS measurements during ascending orbits is smaller during that period than during previous months.

\subsection{SMOS}

The SMOS mission (Kerr et al., 2010) was launched in November 2009, on a sun-synchronous circular orbit with a local equator crossing time at 06:00 a.m. on ascending node. It carries an L-band interferometric radiometer. This new technology allows reconstructing bi-dimensional multiangular images of the L-band brightness temperatures, $\mathrm{Tb}$, with a mean spatial resolution of $40 \mathrm{~km}$. Individual measurements are very noisy so that retrieving a SSS with an accuracy acceptable for oceanographic studies is only possible owing to the combination of multiple $\mathrm{Tb}$ measurements acquired at the same ocean grid point at various incidence angles and polarisations over successive snapshots (Boutin et al., 2004). As described in Boutin et al. (2012), the retrieval scheme implemented in the ESA (European Space Agency) processing uses the Levenberg and Marcquardt iterative algorithm for retrieving SSS, wind speed, sea surface temperature (SST) and total electron content, from the multiangular and polarised information contained in SMOS Tbs along a dwell line. Prior values for wind speed and sea surface temperature are taken from ECMWF (European Centre for Medium-Range Weather Forecasts); in the version considered in our study, errors of $2 \mathrm{~m} \mathrm{~s}^{-1}$ and of $1^{\circ} \mathrm{C}$ have been put on wind components and SST, respectively. First assessment of SMOS SSS retrieved with ESA processing just after the commissioning phase and mapped at typical GODAE scales (Banks et al., 2012; Boutin et al., 2012) has shown good general agreement with respect to SSS climatology, ARGO and ocean model output. Although these studies are very encouraging, they also point out SMOS data deficiencies: large SSS biases related to continents vicinity, to radio frequency interferences and to orbit orientation, the latter being likely due to imperfections of the thermal antenna model (Kainulainen et al., 2012). Deficiencies of direct roughness models at high wind speeds lead to the development of new empirical or semi-empirical roughness models fitted to SMOS measurements (Guimbard et al., 2012; Yin et al., 2012). Using an improved image reconstruction algorithm, Reul et al. (2012) found an accuracy on monthly, $1^{\circ} \times 1^{\circ} \mathrm{SSS}$ of 0.6 globally and 0.4 in the tropics for $90 \%$ of the data and much larger biases in the vicinity of land.

In the present study, level 2 SMOS SSS are from the first SMOS/ESA annual reprocessing campaign in which ESA level 1 v5.04 and level 2 v5.50 processors have been used. In these versions, significant improvements with respect to the flaws listed above have been implemented (see a complete description in the Algorithm Theoretical Basis Document (ATBD) available at: www.argans.co.uk). ESA level 2 SMOS SSS have a mean spatial resolution of $40 \mathrm{~km}$ and are over sampled on an ISEA grid at $15 \mathrm{~km}$ resolution. 
Since these new SMOS SSS have been delivered very recently, no assessment of their accuracy has been published yet. Hence, we first present a global scale validation. We use similar methods as the ones described in Boutin et al. (2012). They are summarized below.

We use ESA level 2 SMOS SSS retrieved with model 1, which makes use of the new (Yin et al., 2012) roughness model; only ascending orbits are considered in order to minimize uncertainties linked to Faraday rotation and to diurnal SST cycle. We build SMOS SSS maps at $1^{\circ} \times 1^{\circ}$ resolution by taking the average of the ESA level 2 SMOS SSS weighted by the variance of the retrieved SSS error and by the mean spatial resolution of each SSS. Precise collocations with ARGO measurements are performed by taking SMOS SSS at $\pm 50 \mathrm{~km}$ and \pm 5 days from ARGO floats. When averaged in these radii, SMOS SSS are weighted the same way as in the map production.

The filtering of the ESA level 2 SMOS SSS differs slightly from previous studies as the definition of flags has changed (see ATBD). We retain grid points flagged as valid, further than $200 \mathrm{~km}$ from the coast, with successful retrieval, with a good fit between measured and modelled Tbs (tests on Chi2 and Chi2_P as defined in ATBD), with less than 20 iterations of the Levenberg and Marquardt retrieval process, no suspect ice and not many outliers; only measurements with low sun glint, low galactic noise are used in the SSS retrieval. In addition, in order to (1) avoid too noisy retrievals at the edge of the swath and (2) imprecision due to lower accuracy of ECMWF forecasts and of our roughness model at very low and high wind speed, we only consider SMOS SSS retrieved in grid points with (1) more than 130 measurements coming from the alias free field of view region (roughly corresponding to SSS retrieved at $\pm 300 \mathrm{~km}$ from the centre of the track) and (2) ECMWF wind speed between 3 and $12 \mathrm{~m} \mathrm{~s}^{-1}$. When averaging ESA level 2 SMOS SSS, only averages made with more than 30 individual SSS are retained. With these criteria, a grid point is seen approximately once every 5 days, during ascending orbits.

\subsection{ARGO}

We use measurements from ARGO floats provided by the Coriolis data centre (http://www.coriolis.eu.org/). We downloaded 23577 profiles with measurements between $4 \mathrm{~m}$ and $10 \mathrm{~m}$ depth between 1 July 2010 and 30 September 2010, as available on the Coriolis web site on 5 May 2012: during the studied period, 14263 profiles have been quality checked (delayed time data). We only use ARGO measurements with a quality flag equal to 1 , in agreement with real time quality checks and, for delayed time data, with statistical consistency checks (Carval et al., 2012).

During the ascent of the float, when the float is at about $5 \mathrm{~m}$ depth from the sea surface, the water pump is stopped in order to avoid damages linked to air pumping. The no pumping leads to inaccurate salinities above that depth. Some com- parisons performed in surface layers of a well mixed area between pumped and nonpumped salinity on an ARVOR float indicate a noise on the nonpumped salinity (at $\sim 2 \mathrm{~m}$ from the last pumped measurement) of 0.025 with respect to 0.005 on pumped salinities. In addition, in case of true salinity stratification linked to rain events, nonpumped measurements would miss most of the freshening. In order to minimize this effect, and given that the pressure measurements of some ARGO floats (e.g. APEX) are not very precise (so that some measurements indicated as measured at $4 \mathrm{~m}$ depth may sometimes be pumped), for the present study we use the closest ARGO salinity to the sea surface, provided it is measured between $4 \mathrm{~m}$ and $10 \mathrm{~m}$ depth, without any interpolation to the surface. We will later refer to this measurement as ARGO SSS.

Global ARGO SSS maps (D2CA1S2 re-analysis product) are produced by IFREMER/LPO Laboratoire de physique des oceans (see a description at: www.ifremer.fr/ lpo/SO-Argo-France). They are derived, after a thorough quality check of ARGO measurements, with the optimal interpolation method described in (Gaillard et al., 2009); they are named ARGO OI in the following. The choice for the time and space scales used in that method results from a compromise between what is known of ocean time and space scales and what can actually be resolved with the ARGO array $\left(3^{\circ}, 10\right.$ days); two scale lengths are considered: the first one is isotropic and equal to $300 \mathrm{~km}$, the second one is set equal to 4 times the average Rossby radius of the area. As a result, we expect these maps being smoother, especially in tropical areas, than SMOS SSS maps averaged over $1^{\circ} \times 1^{\circ}$.

ARGO salinity are on the practical salinity scale PSS-78, defined as a conductivity ratio; following UNESCO (1985) recommendations, salinity on practical salinity scale is unitless. Since L-band brightness temperatures are related to salinity via water permittivity, which mostly depends on sea water conductivity, and since SMOS Tbs are calibrated every two weeks with respect to climatological salinity on practical salinity scale and in order not to use different convention for salinity from various origins, in this paper we apply this no unit convention to both in situ and satellite salinity.

\section{$2.3 \mathrm{SSM} / \mathrm{Is}$ rain rate}

In July-September 2010, the local equator crossing time of the descending nodes of SSM/Is F17 and SSM/Is F16 missions are, respectively, approximately $20 \mathrm{mn}$ before and $40 \mathrm{mn}$ after SMOS ascending node. Hence, numerous SMOS level 2 are collocated with SSM/I rain rates (RR) within this range of time; only the SSM/I RR closest in time with SMOS SSS are kept. SSM/I F15 is also close in time to SMOS passes but we do not consider it in our statistical analysis because of its degradation after August 2006. Nevertheless we use SSM/I F15 RR qualitatively. SSM/Is RR version 7 are downloaded from www.remss.com. 
Table 1. Comparison of SMOS SSS (10 day, $100 \times 100 \mathrm{~km}^{2}$ average) collocated with ARGO SSS in the various regions indicated on Fig. 1.

\begin{tabular}{lrrrr}
\hline & Mean $(\Delta \mathrm{SSS})$ & Std $(\Delta \mathrm{SSS})$ & $\mathrm{Rmse}$ & $N$ \\
\hline $\begin{array}{l}\text { Subtropical Atlantic Ocean } \\
\left(15-30^{\circ} \mathrm{N} ; 45-30^{\circ} \mathrm{W}\right)\end{array}$ & -0.13 & 0.28 & 0.31 & 206 \\
$\begin{array}{l}\text { Tropical Pacific Ocean } \\
\left(5-15^{\circ} \mathrm{N} ; 180-110^{\circ} \mathrm{W}\right)\end{array}$ & -0.23 & 0.35 & 0.42 & 692 \\
$\begin{array}{l}\text { Southern Indian Ocean } \\
\left(40-30^{\circ} \mathrm{S} ; 70-90^{\circ} \mathrm{E}\right)\end{array}$ & 0.04 & 0.39 & 0.39 & 114 \\
$\begin{array}{l}\text { Southern Pacific Ocean } \\
\left(50-40^{\circ} \mathrm{S} ; 180-100^{\circ} \mathrm{W}\right)\end{array}$ & -0.08 & 0.51 & 0.52 & 467 \\
\hline
\end{tabular}

$\Delta$ SSS $=$ SSSsmos-SSSargo

Estimating the accuracy of satellite rain rate at high spatial and temporal resolution is a very difficult task given the variability of precipitation within a satellite pixel and the undersampling of in situ measurements. Considering temporal averages, Bowman et al. (2009) found that SSM/I RR version 6 retrieved by Remote Sensing System are in good agreement with respect to in situ rain gauge measurements in the tropics. Hilburn and Wentz (2008) found that once the diurnal variability of the precipitations is taken into account, the intersatellite SSM/I bias is less than $3 \%$ and, in the tropics, the $\mathrm{SSM} / \mathrm{I} \mathrm{RR}$ is very consistent with the Global Precipitation Climatology Project (GPCP) RR and RR trends.

\section{Results}

\subsection{Validation of SMOS SSS over the global ocean}

The SMOS SSS map averaged over July-September 2010 is compared to the ARGO OI map averaged over the same period in Fig. 1. SSS spatial variability at large-scale is well sensed by SMOS and, with respect to previous version (see for instance Fig. 4 of Boutin et al., 2012), the first ESA annual reprocessing greatly improves the SSS retrieved in the vicinity of land and ice. Nevertheless, biases on the order of -0.5 remain close to continents. SMOS measurements in the northern Atlantic and Pacific Ocean and close to Asian coasts are sorted out by outliers and RFI sorting. Negative biases of SMOS SSS on the border of these regions indicate that RFI sorting remains insufficient. Large positive biases occur in the eastern equatorial Pacific Ocean; the origin of such biases, already observed in the previous version, is still under investigation. In regions with strong SSS gradients, like the Amazon plume, positive and negative biases are very likely due to the smoothing of ARGO OI map with respect to SMOS SSS map. A mean negative bias is observed in a latitudinal band around $10^{\circ} \mathrm{N}$ in the tropical Pacific Ocean.

In order to distinguish the biases linked to the smoothing of the ARGO OI map from SMOS SSS flaws, we further look at differences between individual ARGO float salinity data and the ARGO OI map (Fig. 2, top right) and at differences
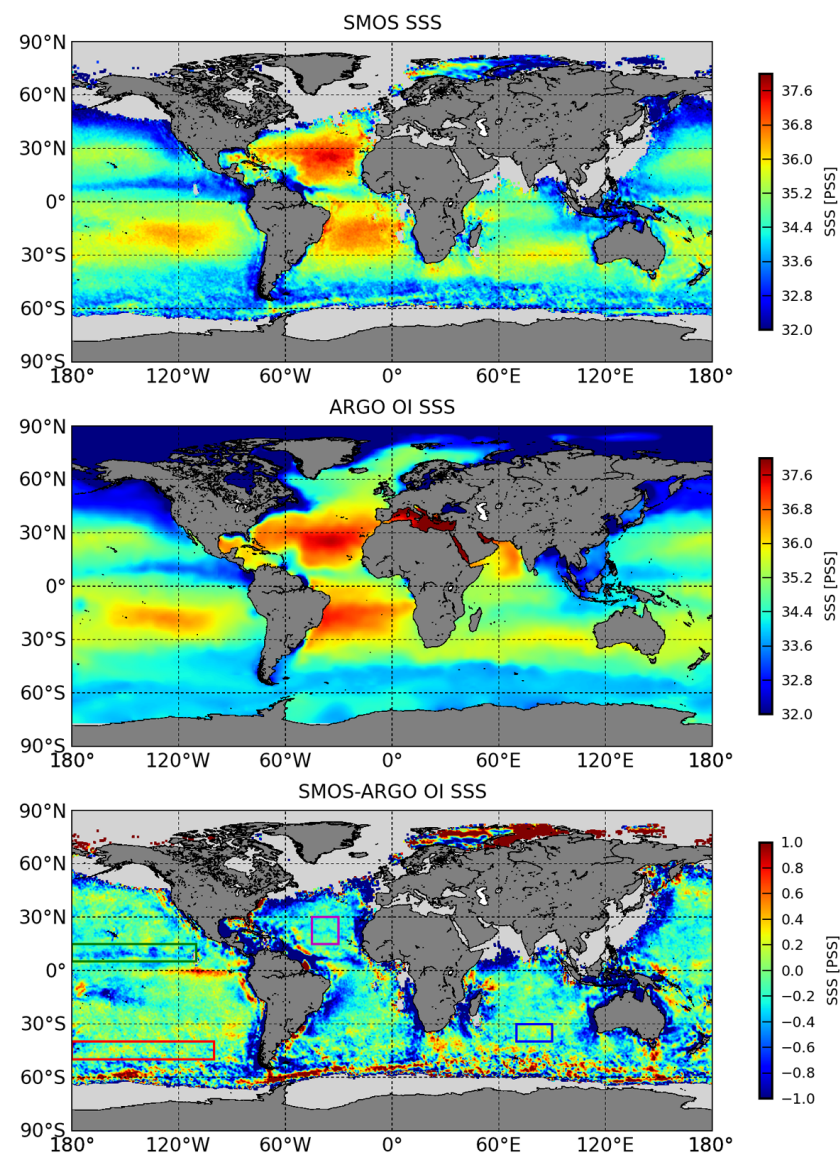

Fig. 1. Maps of SSS averaged from July to September 2010, derived from (top) SMOS ascending orbits, (middle) ARGO OI, SMOSARGO OI (bottom) Difference between SMOS and ARGO OI maps. Color rectangles indicate regions where precise comparisons with ARGO have been performed.

between collocated SMOS and ARGO SSS (Fig. 2, bottom). As expected, differences between ARGO SSS and the ARGO OI map are often outside the $-0.5,0.5$ range in frontal areas like the Amazon plume, the South Atlantic confluence region, and south of the subtropical zone in the Southern Indian Ocean; in all these areas the differences between collocated SMOS and ARGO SSS (Fig. 2, bottom) are usually smaller than SMOS minus ARGO OI (Fig. 2, top, left), showing that SMOS brings complementary information with respect to ARGO OI about SSS variability at $100 \mathrm{~km}-10$ day resolution. Comparisons between ARGO SSS and collocated SMOS SSS are detailed on Fig. 3 and Table 1 in four regions chosen as being far from land and covering various SST conditions and previously studied in Boutin et al. (2012). Standard deviations of the differences are very similar to the ones reported in Boutin et al. (2012); the rms (root mean square) error, rmse, is on the order of 0.3-0.4 in tropical regions and 0.5 in cold regions. The mean bias is $\sim 0.1$ lower in the tropical Pacific Ocean than in other regions. 

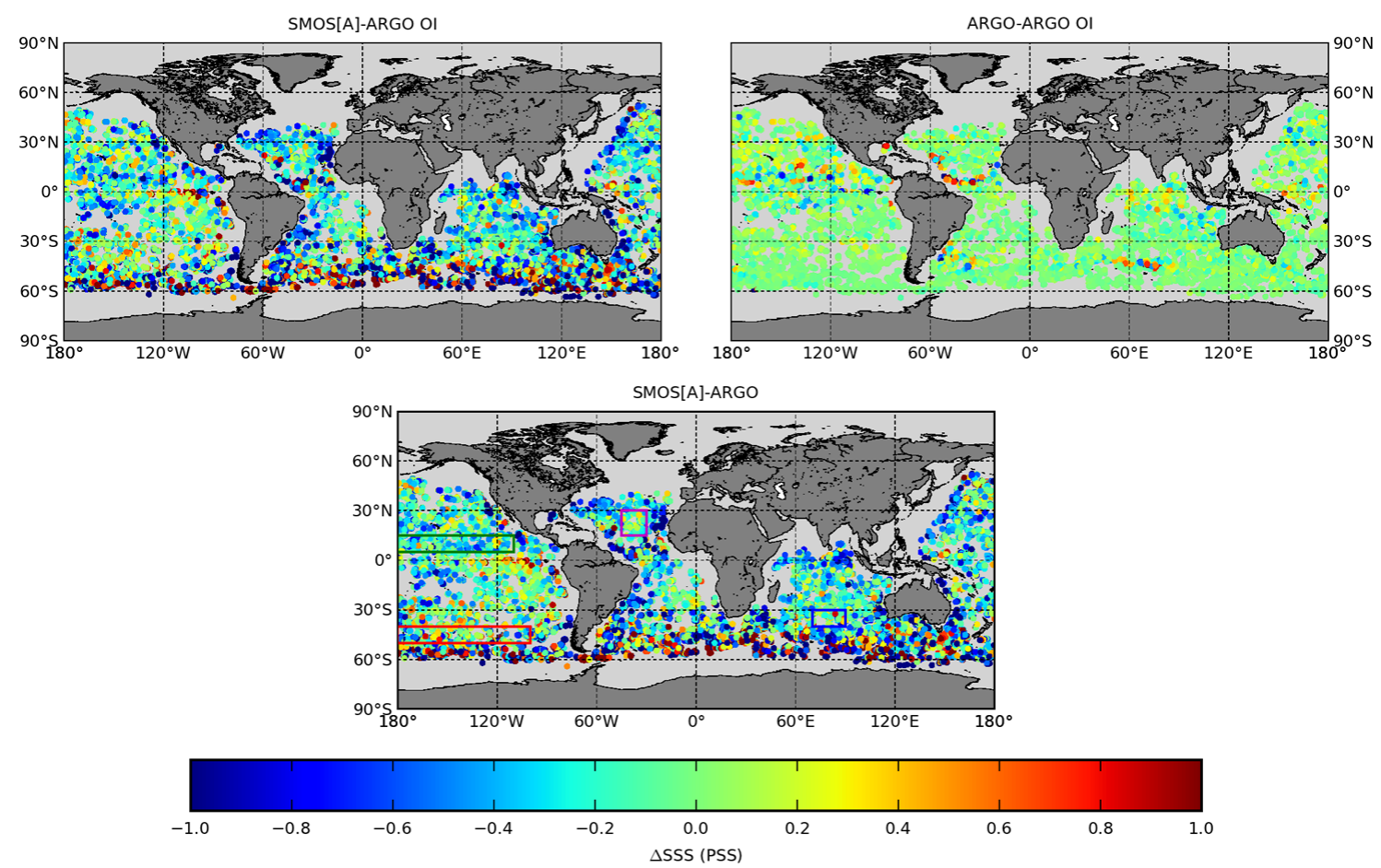

Fig. 2. SSS difference between (top, left) 10 day-100 km SMOS SSS collocated with individual ARGO SSS minus ARGO OI map, (top, right) ARGO SSS minus ARGO OI map, (bottom) 10 day-100 km SMOS SSS minus ARGO SSS. Color rectangles indicate regions where precise comparisons with ARGO data have been performed (see Fig. 3 and Table 1).

\subsection{Influence of rain}

In the northern tropical Pacific region that includes the InterTropical Convergence Zone (ITCZ), for 5 collocations, both ARGO SSS and 10 day-100 km SMOS SSS are fresher by more than 0.7 than the ARGO OI map value (Fig. 2, top). For one of these collocations corresponding to measurements taken on 11 August by the ARGO float no. 4900325, it was possible to get satellite RR close in time to SMOS and ARGO measurements. This vertical ARGO profile (Fig. 4a) detects a freshening of 0.9 between $20 \mathrm{~m}$ and $5 \mathrm{~m}$ depth contrary to the following profile taken by the same ARGO float 10 days later (Fig. 4b): on the 22 August profile, the ARGO salinity between $30 \mathrm{~m}$ and $5 \mathrm{~m}$ depth is much more homogeneous. The salinity at $5 \mathrm{~m}$ depth recorded on 22 August is 0.7 saltier than the one recorded on 11 August. Figure 5a-d indicate that on 11 August, moderate $\left(\sim 1 \mathrm{~mm} \mathrm{~h}^{-1}\right)$ rain lasted for at least $7 \mathrm{~h}$ before the ARGO profile, while on $22 \mathrm{Au}$ gust the two closest satellite RR suggest that no rain occured (Fig. 5h, i), nor the day before (Fig. 5f, g).

The first SMOS pass collocated with the 11 August ARGO profile (Fig. 4a) is 0.1 saltier than the ARGO SSS taken 06:30 later and occurs also under moderate rainy conditions (Fig. 5a, b). The second SMOS pass occurs 5 days after the first SMOS pass, under nonrainy conditions (Fig. 5e) and is 0.5 saltier. The SMOS SSS during the first SMOS pass collocated with the 22 August ARGO profile (Fig. 4b) differs by only 0.1 from the ARGO SSS and it also occurs in nonrainy conditions (Fig. 5f, g). SMOS SSS during the second SMOS pass is 0.3 fresher than during the first pass and is taken under low rain conditions.

The large SSS variation (0.7) measured by this ARGO float at a 10-day interval and by the collocated SMOS measurements over several SMOS passes illustrates, in this particular case, the influence of the rain timing on the SMOS - ARGO SSS differences in the northern tropical Pacific Ocean region. Hence taking a collocation radius of 5 days and $100 \times 100 \mathrm{~km}^{2}$ (while huge variability appears on satellite RR from one $25 \mathrm{~km}$ pixel to another; Fig. 5) in which we average SMOS SSS around ARGO SSS is not adequate in a rainy region and part of the noise and bias reported in Table 1 is likely due to rain induced variability.

The most pronounced freshening linked to rain events is expected to occur a few hours following the rain event. Hence owing to the numerous crossing between SMOS passes and SSM/Is F16 and F17 passes within a temporal interval of $-40 \mathrm{mn}$ and $+80 \mathrm{mn}$, we colocate level 2 SMOS SSS with the closest SSM/Is RR and we classify the SMOS-ARGO differences (without any averaging of level 2 SMOS SSS) as a function of the closest SSM/Is RR. The expected error on the level 2 SMOS SSS derived by the retrieval algorithm from the Tb measurement theoretical error is 0.5 . Without any RR sorting, the statistical distribution of the differences 
Table 2. Statistics of SMOS level 2 SSS minus ARGO SSS (matchups at $\pm 50 \mathrm{~km}$ and $\pm 80 \mathrm{mn}$ from SSM/I rain rates).

\begin{tabular}{lrrrr}
\hline & Mean $(\Delta \mathrm{SSS})$ & $\mathrm{Std}(\Delta \mathrm{SSS})$ & $\mathrm{Skew}(\Delta \mathrm{SSS})$ & $N$ \\
\hline Tropical Pacific $\left(5-15^{\circ} \mathrm{N}, 110-180^{\circ} \mathrm{W}\right)$ & & & & \\
\hline All collocations & -0.20 & 0.62 & -0.38 & 38543 \\
No Rain $\left(\mathrm{RR}<0.1 \mathrm{~mm} \mathrm{~h}^{-1}\right)$ & -0.13 & 0.56 & 0.01 & 29084 \\
Rainy $\left(\mathrm{RR} \geq 0.1 \mathrm{~mm} \mathrm{~h}^{-1}\right)$ & -0.40 & 0.73 & -0.58 & 9459 \\
\hline Subtropical Atlantic $\left(15-30^{\circ} \mathrm{N}, 45-30^{\circ} \mathrm{W}\right)$ & & & & \\
\hline All collocations & -0.08 & 0.57 & -0.04 & 12728 \\
No Rain $\left(\mathrm{RR}<0.1 \mathrm{~mm} \mathrm{~h}^{-1}\right)$ & -0.06 & 0.56 & 0.03 & 12122 \\
Rainy $\left(\mathrm{RR} \geq 0.1 \mathrm{~mm} \mathrm{~h}^{-1}\right)$ & -0.38 & 0.63 & -0.52 & 606 \\
\hline
\end{tabular}

$\Delta$ SSS $=$ SSSsmos-SSSargo.

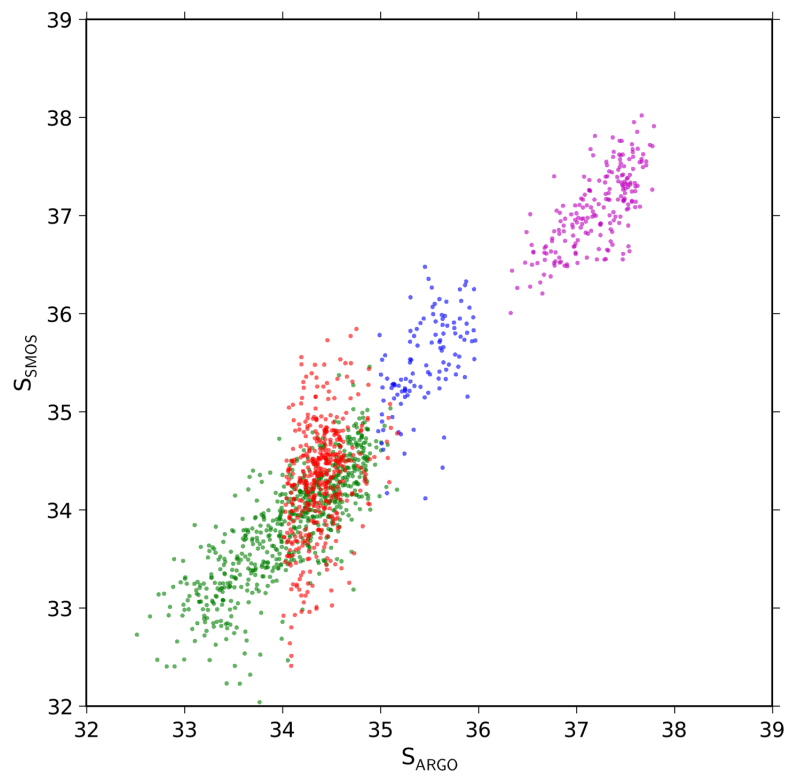

Fig. 3. Scatter plot of SMOS SSS versus ARGO SSS for the various regions indicated on Fig. 1 and in Table 1 (green: tropical Pacific Ocean; purple: subtropical Atlantic Ocean; blue: Soutern Indian Ocean; red: Southern Pacific Ocean).

is skewed towards negative differences (Fig. 6 and Table 2); when SMOS observations concomitant with rain events are removed from the comparison, the negative skewness disappears, and statistics of the SMOS-ARGO differences in the tropical Pacific Ocean and in the subtropical Atlantic Ocean become closer, although the mean bias remains more negative in the tropical Pacific Ocean (Table 2). When only SMOS observations concomitant with rain events are considered, the statistical distribution is more skewed towards negative differences. For this latter case, we find a negative dependency of the SMOS-ARGO SSS differences with respect to SSM/Is RR of $-0.17 \mathrm{~mm}^{-1} \mathrm{~h}^{-1}$, that is a freshening of 1.7 for a RR of $10 \mathrm{~mm} \mathrm{~h}^{-1}$.

\section{Error sources}

In ESA SMOS SSS processing, no correction is applied for the atmospheric contribution of liquid clouds and rain as there is no simultaneous measurements onboard the satellite of the necessary parameters. In addition, rain is difficult to predict locally in exactly the right place and time (e.g. Geer et al., 2008): SSM/Is RR and ECMWF RR collocated in SMOS pixels are very poorly correlated $\left(R^{2}=0.02\right)$ indicating that ECMWF RR is a very poor indicator of local rain and cannot be used for estimating rain atmospheric contribution in the SMOS SSS processing. Nevertheless, the contribution of atmospheric absorption and scattering by clouds and rain to the radiometric signal is much smaller at L-band than at higher frequency and the Rayleigh approximation for estimating the absorption and scattering by raindrops is estimated to remain valid for RR up to $10 \mathrm{~mm} \mathrm{~h}^{-1}$ (Ulaby et al., 1981). Using this approximation, studies prior to SMOS and Aquarius launch (Peichl et al., 2004; Wentz, 2005) show that the atmospheric correction should be a positive bias of about $0.22 \mathrm{~K}$ on first Stokes parameter for a RR of $10 \mathrm{~mm} \mathrm{~h}^{-1}$; given the sea surface temperature of the tropical Pacific Ocean, this translates to a negative bias on the SSS of about -0.3 for a RR of $10 \mathrm{~mm} \mathrm{~h}^{-1}$. Hence, taking into account this effect would reduce the slope of $\mathrm{dSSS} / \mathrm{dRR}$ shown in Fig. 7 to $-0.14 \mathrm{~mm}^{-1} \mathrm{~h}^{-1}$, which remains nonnegligible.

Apart from the atmospheric effect, very little is known about the impact of the modification of the ocean surface by rain on L-band Tbs. Actually, sea surface waves may be affected by rain splash, rain created ring waves and rain damping effect, the importance of these effects being dependent on their wavelength. According to Contreras and Plant (2006), the resulting effect on the backscattering signal depends on the measured wavelength: the backscattering at $\mathrm{Ku}, \mathrm{Ka}$ and $\mathrm{C}$-band is dominated by an enhancement effect whereas the rain damping is the dominant effect on L-band backscattering. The L-band Tb are mainly affected by scattering by centimeter and decameter wavelengths (Dinnat, 2003), so that the effect of rain on L-band $\mathrm{Tb}$ is expected to be much 
a) ARGO profile on 11/8 20:00 UTC

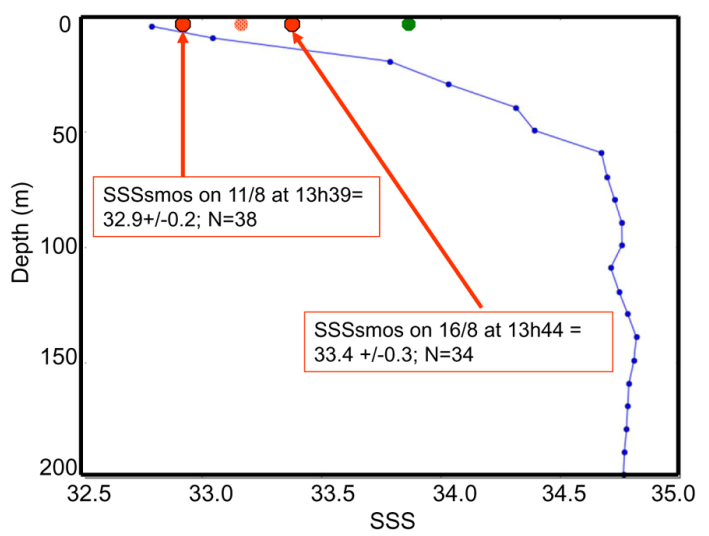

b) ARGO profile on 22/08 6:52 UTC

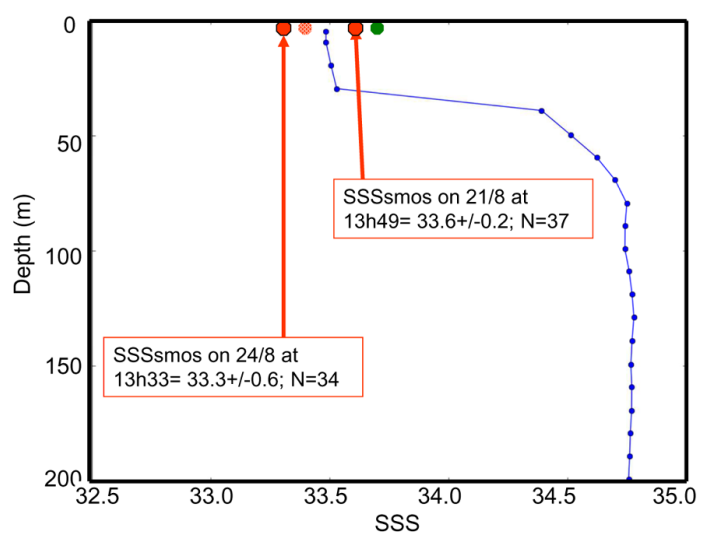

Fig. 4. Two successive ARGO profiles taken by float 4900325 (blue curve) on (a) 11 August 20:00 UTC (Latitude $=12.4^{\circ} \mathrm{N}$, Longitude $=117.6^{\circ} \mathrm{W}$ ) and (b) 22 August 06:52 UTC (Latitude: $12.2^{\circ} \mathrm{N}$, Longitude: $\left.117.8^{\circ} \mathrm{W}\right)$. Mean SMOS SSS collocated with these profiles in a radius of 5 days and $50 \mathrm{~km}$ are indicated by a red dotted point. In each case, two SMOS passes have participated to these collocations: mean SMOS SSS corresponding to each pass is indicated as a red filled point. The corresponding ARGO OI SSS in August is indicated by the green point. Satellite RR corresponding to these periods are indicated on Fig. 5.

smaller than at higher frequencies, but it may be nonnegligible for our purpose and is likely to depend on the geometry of the measurement. If the rain damping was the dominant factor affecting $\mathrm{L}$-band $\mathrm{Tb}$, it would bring a $\mathrm{Tb}$ decrease (i.e. an increase of SSS) which is not what we observe. However, more work is needed to quantify this effect.

ECMWF wind speed has been shown, when compared with buoy data, to be less precise in presence of rain (Portabella et al., 2012). In order to explain a -1.4 bias on the SSS (as the one we find at $10 \mathrm{~mm} \mathrm{~h}^{-1}$ after correcting for the atmospheric effect), the retrieved SMOS wind speed should be systematically biased high by $5 \mathrm{~m} \mathrm{~s}^{-1}$. Looking at the differences between ECMWF wind speed (used as prior in the SMOS SSS retrieval) and SMOS retrieved wind speed, we

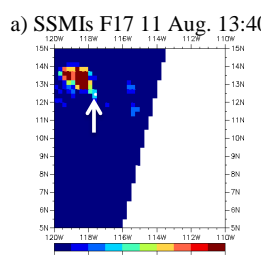

d) AMSRE 11 Aug. 20:55

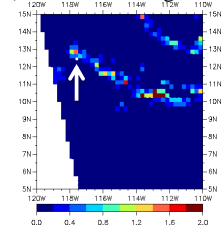

f) SSMIs F17 21 Aug. 13:24

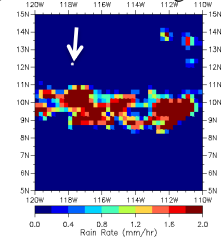

h) SSMI F15 22 Aug. 1:20

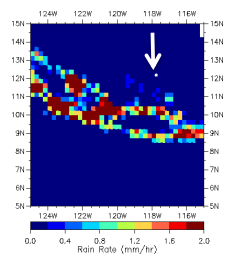

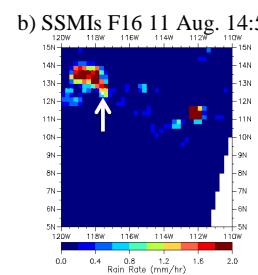

g) SSMIs F16 21 Aug. 14:28

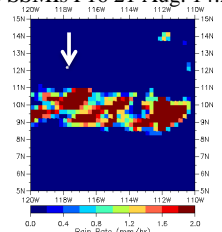

i) AMSRE 22 Aug. 9:40

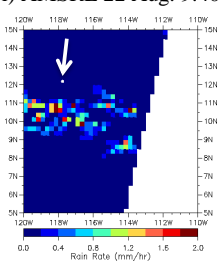

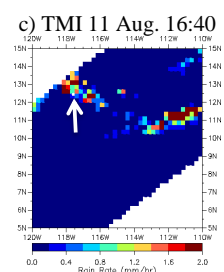

e) SSMI F15 16 Aug. 13:36

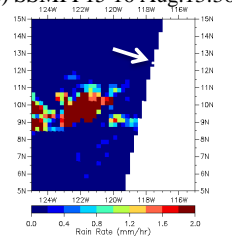

Fig. 5. Satellite RR close in space and time to ARGO profiles and SMOS passes shown in Fig. 4. The location of the ARGO float is indicated by a white point and a white arrow.

did not find any significant trend correlated with SSM/Is RR $\left(R^{2}=0.04\right)$. Although in presence of rain Portabella et al. (2012) indicate an increase of noise in ECMWF wind speed, no systematic bias of several $\mathrm{m} \mathrm{s}^{-1}$ has been demonstrated, so that the deficiencies of ECMWF wind speed in presence of rain cannot explain systematically low biased SSS.

Although the spatial variability of rain within a satellite pixel may be large, this effect should have a relatively small impact in our study because the spatial resolution of SSM/I RR (nominally $32 \mathrm{~km}$ ) is comparable to SMOS spatial resolution $(\sim 40 \mathrm{~km})$.

Rain is often associated with a cooling of the sea surface of a few tenths of degrees (Reverdin et al., 2012). However, in the warm tropical waters, a cooling of $0.2^{\circ} \mathrm{C}$ would result to an increase of $\mathrm{Tb}$ of the order of $0.02 \mathrm{~K}$, leading to a decrease of $\sim 0.03$ in SMOS retrieved salinity. This effect is an order of magnitude smaller than what we observe.

The variation of the surface salinity after a rain event is expected to be the strongest during the hour following a rain event and to vary with the measurement depth (e.g. Reverdin et al., 2012) so that it would have been better to look at the stratification effect between $1 \mathrm{~cm}$ and $5 \mathrm{~m}$ depth using SMOS and ARGO SSS collocated within an hour. However, during 


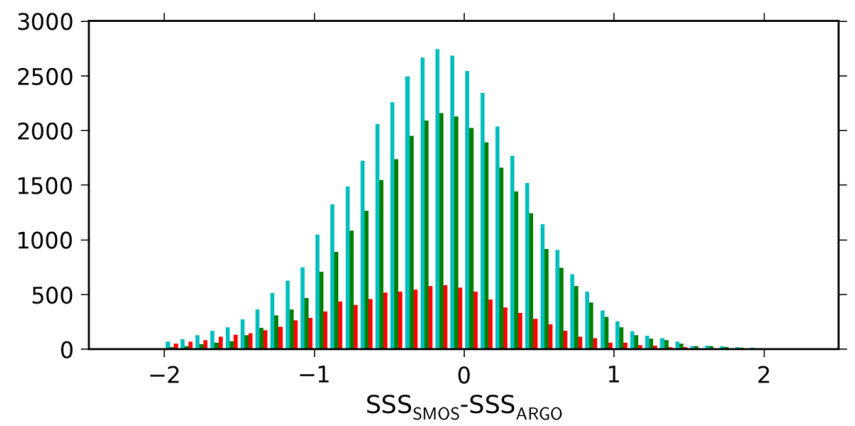

Fig. 6. Statistical distribution of SMOS SSS minus ARGO SSS in the tropical Pacific Ocean for various sortings on SSM/I rain rates; blue: all collocations (without any rain sorting); green: nonrainy cases (SSM/I rain rates less than $0.1 \mathrm{~mm} \mathrm{~h}^{-1}$ ); red: rainy cases $\left(\mathrm{SSM} / \mathrm{I}\right.$ rain rates larger than $\left.0.1 \mathrm{~mm} \mathrm{~h}^{-1}\right)$. Corresponding statistics are indicated in Table 1.

the time period of the present study, there were no collocations of SMOS and ARGO SSS within a radius of one hour.

\section{Conclusions and perspectives}

Satellite L-band radiometry provides for the first time a measure of salinity in the first centimeter of the sea surface and a synoptic coverage better than the one of ARGO at the expense of the precision of SSS individual measurements.

The optimal interpolation of ARGO salinity sampled approximately every $3^{\circ}$ and 10 days smoothes the SSS variability measured by individual ARGO floats; locally, in frontal and rainy regions, the SSS variability is larger than 0.5 (see Fig. 2) and it is consistently recorded by ARGO measurements and SMOS SSS averaged over 10 days and $100 \times 100 \mathrm{~km}^{2}$. We estimate SMOS SSS accuracy to be $0.3-$ 0.4 in tropical and subtropical regions and 0.5 in cold regions; a bias of $\sim-0.5$ remains close to continents.

Both ARGO and SMOS measurements in the tropical Pacific Ocean show that SSS vary by more than 0.5 within 10 days in case of rainy events. The nonsorting of SMOS SSS concomitant with rainy events in SMOS-ARGO collocations within 10 days and $100 \mathrm{~km}$ is responsible for (1) a mean -0.1 negative bias over 3 months between $5^{\circ} \mathrm{N}$ and $15^{\circ} \mathrm{N}$ in the tropical Pacific region with respect to nonrainy conditions and with respect to the subtropical Atlantic region, and (2) a negative skewness of the statistical distribution of SMOS minus ARGO SSS difference (Fig. 6). Given that the whole set of SMOS-ARGO collocations also includes the situations with ARGO measurements concomitant with rain events collocated with SMOS measurements under nonrainy conditions, these results indicate a systematic freshening of SMOS SSS in rainy conditions and is likely a signature of the vertical salinity stratification between the first centimeter of the sea surface layer sampled by SMOS and the $5 \mathrm{~m}$ depth sampled by ARGO.

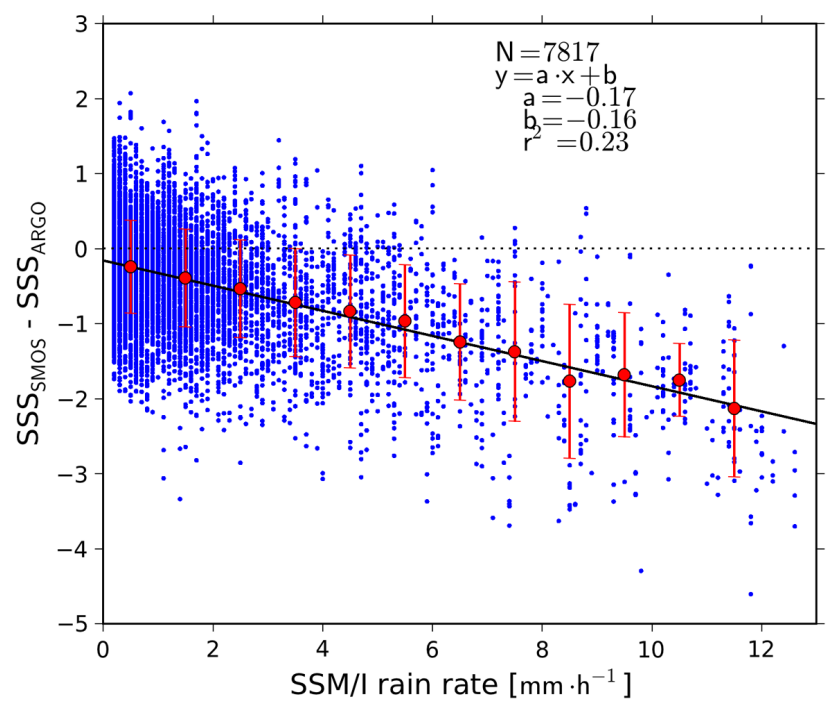

Fig. 7. SMOS level 2 SSS minus ARGO SSS as a function of SSM/I RR in the tropical Pacific region. Only pairs with SSM/I RR larger than $0.1 \mathrm{~mm} \mathrm{~h}^{-1}$ are plotted. Mean and standard deviation of the differences per RR classes are indicated as red points and error bars. The least squares fit derived from individual measurements (black line) closely follows the mean tendency in RR classes; it indicates a slope of -0.17 per $\mathrm{mm} \mathrm{h}^{-1}$ and a $R^{2}$ coefficient of 0.23 .

Some of the SMOS observed freshening in the presence of rainfall could result from the rain atmospheric contribution, not corrected in the SMOS SSS retrieval, but it can only explain $20 \%$ of the observed freshening. After correction of this effect, we estimate a freshening of $-0.14 \mathrm{~mm}^{-1} \mathrm{~h}^{-1}$. There might be also a contribution due to changes in surface waves or wind under rainy conditions, but which is not likely to be of that magnitude. Nevertheless, the rain-surface waves modification should be looked at in more detail in future studies and a precise validation of SMOS SSS under rainy conditions would be necessary. This is a very difficult task as it would require very precise temporal collocation of SMOS and in situ salinity measured in the first centimeter of the sea surface. In addition, on a majority of in situ platforms recording SSS (e.g. ARGO floats, surface drifters), wind speed and rain rate are not measured.

Concerning calibration and validation of satellite L-band $\mathrm{Tb}$ and retrieved SSS using in situ SSS recorded at a few meters depth, we recommend considering only nonrainy conditions.

In the future, it is hoped that the analysis and understanding of the salinity stratification effect will improve owing to the ongoing international efforts conducted for performing large number of measurements of the salinity closer to the sea surface than traditional in situ measurements and at several depths close to the sea surface, either using autonomous drifters (Reverdin et al., 2012) or high resolution profilers, like the ARGO-STS (Anderson and Riser, 2012) or the ASIP profiler (Ward et al., 2004; Vialard et al., 2009). In addition, 
the long time series of SMOS and Aquarius SSS together with these new measurements will allow wider validation of new remotely sensed SSS.

The combination of new satellite SSS and in situ salinity measured deeper provides new information about salinity stratification in the upper ocean which should contribute to a better understanding of air-sea interaction processes. These processes should be taken into account by ocean models when assimilating satellite SSS under rainy conditions.

Acknowledgements. SSM/I data are produced by Remote Sensing Systems and sponsored by the NASA Earth Science MEaSUREs DISCOVER Project. Data are available at: www.remss.com. We thank Hugo Bellenger for interesting discussions about tropical rain cells. This work has been supported by GLOSCAL SMOS $\mathrm{Cal} /$ Val ESA and CNES/TOSCA project and by the SMOS ESA Expert Support Laboratory project.

Edited by: B. Ward

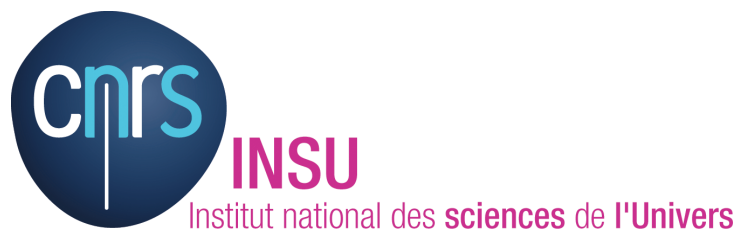

The publication of this article is financed by CNRS-INSU.

\section{References}

Anderson, J. and Riser, S.: Near Surface variability of Temperature and Salinity: Observations from Profiling Floats, Aquarius/SACD Science Team Meeting, Buenos Aires, Argentina, 11-13 April 2012, 2012.

Banks, C. J., Gommenginger, C. P., Srokosz, M. A., and Snaith, H. M.: Validating SMOS Ocean Surface Salinity in the Atlantic With Argo and Operational Ocean Model Data, IEEE Trans. Geosci. Remote Sens., 50, 1688-1702, doi:10.1109/tgrs.2011.2167340, 2012.

Boutin, J., Waldteufel, P., Martin, N., Caudal, G., and Dinnat, E.: Surface Salinity Retrieved from SMOS Measurements over the Global Ocean: Imprecisions Due to Sea Surface Roughness and Temperature Uncertainties, Journal of Atmospheric and Oceanic Technology, 21, 1432-1447, doi:10.1175/15200426(2004)021;1432: $\operatorname{ssrfsm}_{i} 2.0 . \operatorname{co} ; 2,2004$.

Boutin, J., Martin, N., Xiaobin, Y., Font, J., Reul, N., and Spurgeon, P.: First Assessment of SMOS Data Over Open Ocean: Part II - Sea Surface Salinity, IEEE Trans. Geosci. Remote Sens., 50, 1662-1675, doi:10.1109/tgrs.2012.2184546, 2012.

Bowman, K. P., C. R. Homeyer, and D. G. Stone: A comparison of oceanic precipitation estimates in the tropics and subtropics, J. Appl. Meteorol. Climatol., 48, 1335-1344, 2009.

Carval, T., Keeley, B., Takatsuki, Y., Yoshida, T., Loch, S., Schmid, C., Goldsmith, R., Wong, A., McCreadie, R., Thresher, A., and Tran, A.: Argo User's Manual v2.4, IFREMERreference cordo/dti-mut/02-084, 85, 2012.
Contreras, R. F. and Plant, W. J.: Surface effect of rain on microwave backscatter from the ocean: Measurements and modeling, J. Geophys. Res., 111, C08019, doi:10.1029/2005jc003356, 2006.

Cravatte, S., Delcroix, T., Zhang, D., McPhaden, M. J., and Leloup, J.: Observed freshening and warming of the western Pacific warm pool, Clim. Dyn., 33, 565-589, doi:10.1007/s00382-0090526-7, 2009.

Dinnat, E.: De la détermination de la salinité de surface des océans à partir de mesures radiométriques hyperfréquences en bande $\mathrm{L}$, University Paris 6, Paris, 271 pp., 2003.

Durack, P. J., Wijffels, S. E., and Matear, R. J.: Ocean Salinities Reveal Strong Global Water Cycle Intensification During 1950 to 2000, Science, 336, 455-458, doi:10.1126/science.1212222, 2012.

Gaillard, F., Autret, E., Thierry, V., Galaup, P., Coatanoan, C., and Loubrieu, T.: Quality Control of Large Argo Datasets, J. Atmos. Ocean. Tech., 26, 337-351, doi:10.1175/2008jtecho552.1, 2009.

Geer, A. J., Bauer, P., and Lopez, P.: Lessons learnt from the operational $1 \mathrm{D}+4 \mathrm{D}$-Var assimilation of rain- and cloud-affected SSM/I observations at ECMWF, Q. J. R. Meteorol. Soc., 134, 1513-1525, doi:10.1002/qj.304, 2008.

Gordon, A. L. and Giulivi, C. F.: Sea surface salinity trends over fifty years within the subtropical north Atlantic, Oceanogr., 21, 20-29, doi:10.5670/oceanog.2008.64, 2008.

Guimbard, S., Gourrion, J., Portabella, M., Turiel, A., Gabarro, C., and Font, J.: SMOS Semi-Empirical Ocean Forward Model Adjustment, IEEE Trans. Geosci. Remote Sens., 50, 1676-1687, doi:10.1109/tgrs.2012.2188410, 2012.

Hénocq, C., Boutin, J., Reverdin, G., Petitcolin, F., Arnault, S., and Lattes, P.: Vertical Variability of Near-Surface Salinity in the Tropics: Consequences for L-Band Radiometer Calibration and Validation, J. Atmos. Ocean. Tech., 27, 192-209, doi:10.1175/2009jtecho670.1, 2010.

Hilburn, K. A. and F. J. Wentz: Intercalibrated passive microwave rain products from the Unified Microwave Ocean Retrieval Algorithm (UMORA), J. Appl. Meteorol. Climatol., 47, 778-794, 2008.

Kainulainen, J., Colliander, A., Closa, J., Martin-Neira, M., Oliva, R., Buenadicha, G., Rubiales Alcaine, P., Hakkarainen, A., and Hallikainen, M. T.: Radiometric Performance of the SMOS Reference Radiometers - Assessment After One Year of Operation, IEEE Trans. Geosci. Remote Sens., 50, 1367-1383, doi:10.1109/tgrs.2011.2177273, 2012.

Kerr, Y. H., Waldteufel, P., Wigneron, J. P., Delwart, S., Cabot, F., Boutin, J., Escorihuela, M. J., Font, J., Reul, N., Gruhier, C., Juglea, S. E., Drinkwater, M. R., Hahne, A., Martin-Neira, M., and Mecklenburg, S.: The SMOS Mission: New Tool for Monitoring Key Elements ofthe Global Water Cycle, Proceedings of the IEEE, 98, 666-687, doi:10.1109/jproc.2010.2043032, 2010.

Lagerloef, G., Boutin, J., Chao, Y., Delcroix, T., Font, J., Niiler, P., Reul, N., Riser, S., Schmitt, R., Stammer, D., and Wentz, F.: Resolving the Global Surface Salinity Field and Variations by Blending Satellite and In Situ Observations, Oceanobs'09: Sustained Ocean Observations and Information for Society Venise, Italy, 21-25 September 2009, ESA Publication WPP306, doi:10.5270/OceanObs09.cwp.51, 2010.

Mecklenburg, S., Drusch, M., Kerr, Y. H., Font, J., MartinNeira, M., Delwart, S., Buenadicha, G., Reul, N., Daganzo- 
Eusebio, E., Oliva, R., and Crapolicchio, R.: ESA's Soil Moisture and Ocean Salinity Mission: Mission Performance and Operations, IEEE Trans. Geosci. Remote Sens., 50, 1354-1366, doi:10.1109/tgrs.2012.2187666, 2012.

Peichl, M., Wittmann, V., Anterrieu, E., Picard, B., Skou, N., and Solbjerg, S.: Scientific inputs for the SMOS Level 1 Processor development, Final report for ESA contract No. 10508/02/NL/GS, DLR, Munich, 2004.

Portabella, M., Stoffelen, A., Lin, W., Turiel, A., Verhoef, A., Verspeek, J., and Ballabrera-Poy, J.: Rain Effects on ASCATRetrieved Winds: Toward an Improved Quality Control, IEEE Trans. Geosci. Remote Sens., 50, 2495-2506, doi:10.1109/tgrs.2012.2185933, 2012.

Reul, N., Tenerelli, J., Boutin, J., Chapron, B., Paul, F., Brion, E., Gaillard, F., and Archer, O.: Overview of the First SMOS Sea Surface Salinity Products, Part 1: Quality Assessment for the Second Half of 2010, IEEE Trans. Geosci. Remote Sens., 50, 1636-1647, doi:10.1109/tgrs.2012.2188408, 2012.

Reverdin, G., Morisset, S., Boutin, J., and Martin, N.: Rain-induced variability of near sea-surface $\mathrm{T}$ and $\mathrm{S}$ from drifter data, J. Geophys. Res., 117, C02032, doi:10.1029/2011jc007549, 2012.

Soloviev, A. and Lukas, R.: Observation of Spatial Variability of Diurnal Thermocline and Rain-Formed Halocline in the Western Pacific Warm Pool, J. Phys. Oceanogr., 26, 2529-2538, doi:10.1175/1520-0485(1996)026;2529:oosvod 2 2.0.CO;2, 1996.

Soloviev, A. and Lukas, R.: Observation of large diurnal warming events in the near-surface layer of the western equatorial Pacific warm pool, Deep-Sea Res. Pt. I, 44, 1055-1076, doi:10.1016/s0967-0637(96)00124-0, 1997.

Terray, L., Corre, L., Cravatte, S., Delcroix, T., Reverdin, G., and Ribes, A.: Near-Surface Salinity as Nature's Rain Gauge to Detect Human Influence on the Tropical Water Cycle, J. Climate, 25, 958-977, doi:10.1175/jcli-d-10-05025.1, 2011.
Ulaby, F. T., Moore, R. K., and Fung, A. K.: Microwave Remote Sensing - Active and Passive: Vol 1: Microwave Remote Sensing Fundamentals and Radiometry, ARTECH House, Norwood, MA 02062, 456 pp., 1981.

UNESCO: The international system of units (SI) in oceanography, UNESCO Technical Papers No. 45, IAPSO Pub. Sci. No. 32, Paris, France, 1985.

Vialard, J., Duvel, J. P., McPhaden, M. J., Bouruet-Aubertot, P., Ward, B., Key, E., Bourras, D., Weller, R., Minnett, P., Weill, A., Cassou, C., Eymard, L., Fristedt, T., Basdevant, C., Dandonneau, Y., Duteil, O., Izumo, T., de Boyer Montégut, C., Masson, S., Marsac, F., Menkes, C., and Kennan, S.: Cirene: Air-Sea Interactions in the Seychelles - Chagos Thermocline Ridge Region, Bull. Am. Meteorol. Soc., 90, 45-61, doi:10.1175/2008bams2499.1, 2009.

Ward, B., Wanninkhof, R., Minnett, P. J., and Head, M. J.: SkinDeEP: A Profiling Instrument for Upper-Decameter Sea Surface Measurements, J. Atmos. Ocean. Tech., 21, 207-222, doi:10.1175/1520-0426(2004)021;0207:sapifu;2.0.CO;2, 2004.

Wentz, F. J.: The Effect of Clouds and Rain on the Aquarius Salinity Retrieval, Remote Sensing System Technical Memorandum 3031805, Santa Rosa, California, 2005.

Yin, X., Boutin, J., Martin, N., and Spurgeon, P.: Optimization of L-Band Sea Surface Emissivity Models Deduced From SMOS Data, IEEE Trans. Geosci. Remote Sens., 50, 1414-1426, doi:10.1109/tgrs.2012.2184547, 2012.

Zhang, Y. and Zhang, X.: Ocean haline skin layer and turbulent surface convections, J. Geophys. Res., 117, C04017, doi:10.1029/2011jc007464, 2012. 